\title{
Ammunition Delivery Network Optimization Method for Destruction Road Restoring
}

\author{
Ou Qi ${ }^{1, ~ a}$, Wenhua Shi' ${ }^{2, ~ b}$, Lei Zhang ${ }^{3, c}$, Jian $\mathrm{Han}^{4, \mathrm{~d}}$ \\ ${ }^{1}$ Army Academy of Amored Forces, Changchun, China \\ ${ }^{2}$ The Army of 95795, Guilin, China \\ ${ }^{3}$ Changchun Military Representative Office of Shenyang Military Representative Bureau of Ground \\ Force, Changchun, China \\ ${ }^{4}$ Logistic University of PAP, Tianjin, China \\ ahaikuotiankongru@163.com, ${ }^{b} 793468386 @ q q . c o m,{ }^{c}$ fanhuayishu0630@163.com, ${ }^{d}$ hjerpao@hotm \\ ail.com
}

Keywords: Ammunition delivery; Destruction road; Broken road repair; Transport ways.

\begin{abstract}
For the step demand can not be done with by traditional network optimization that will make optimization result unstable when applying to military operation other than war areas, a ammunition delivery network optimization model is put forward. The optimization question is divided into road repair level and transport ways select level. Optimization is done by Monte Carlo simulation for road repair level. Optimization is done by genetic algorithm for transport ways select level. The step demand calculation is avoided by the level division. Optimization result stability is confirmed by the division. The model effectiveness is checked out by residual analysis. Optimization of road repair and transport ways select can be done by this model in military operation other than war area.
\end{abstract}

\section{Introduction}

Transportation network optimization is an important part of logistics scheduling optimization. The main role is to reduce unnecessary waiting time by opening up or repair the damaged part of road, which is an important means to improve the allocation efficiency of materials and equipment[1].

Operation other than war breaks out suddenly. Time and region is uncertain. In order to save costs, small amount equipment is stored in usual. When the operation break out, large amount equipment is temporary financed, which is the main parts of military operation other than war support equipment[2]. The ammunition delivery has the following characteristics: (1) Equipment is collected for temporary use, the failure law in bad natural conditions is unknown; (2) The task early loss intensity and support pressure is heavy. But the task late loss intensity and support pressure is light; (3) Natural environment is complex and changeable. Support demand is random and discontinuous [3].

The ammunition delivery is the main equipment to carry out military operation other than war. The transport network efficiency is vital for military operation other than war carrying out. This is a 
complex problem involving security workers, equipment and command[4,5]. Unified Ammunition delivery and different management for working time and resting bring great pressure to equipment support. In order to deal with military operation other than war tasks effectively, equipment support system optimization is needed. Transportation network optimization is an important part of equipment support system optimization[6].

In order to solve this problem, a military operation other than war unit is set as the research object. A system consists of military operation other than war tasks, military personnel, military operations other than war equipment and ammunition delivery is analyzed using analogy methods. Military operation other than war strength allocation in single model is realized. The basis is provided for military operation other than war strength configuration by the model.

\section{Monte-Carlo Simulation and Genetic Algorithm}

Monte Carlo simulation is a method using statistics method to get basically variables under accurate variable distribution and approximate exact distribution can not be got.

Combined with non war military operations practice, the optimization object is set to minimization of resources demand nodes that unable to meet and shortest time of resources demand nodes that resources demand nodes that able to meet.

Table 1 Monte Carlo simulation boundary condition

\begin{tabular}{|l|l|}
\hline Model paraments & Paraments boundary \\
\hline Paraments are to assess & Load paraments \\
\hline Variables property & $\begin{array}{l}\text { Independent variables are Latent variables } \\
\text { Independent variables are manifest variables }\end{array}$ \\
\hline Number of Independent variables & $\begin{array}{l}\text { Number of independent t Variables is unknown, and need } \\
\text { to assess }\end{array}$ \\
\hline $\begin{array}{l}\text { Relationship among independent } \\
\text { variables }\end{array}$ & Variables are independent of each other \\
\hline
\end{tabular}

Assume that the equipment support the independent variables are independent of each other, factors that transportation resources mutual interfere each other result in decreasing of equipment effects is not considered in this paper.

$$
\min z=\sum_{i=1}^{n}\left[E\left(\xi_{i}\right)-\sum_{k=1}^{K} r_{k i}\right]+\alpha \sum_{i=1}^{n} \sum_{k=1}^{K} \delta_{k i} r_{k i}
$$

In the formula $8, \sum_{i=1}^{n}\left[E\left(\xi_{i}\right)-\sum_{k=1}^{K} r_{k i}\right]$ is the resource unable to meet in the resources demand nodes. $\sum_{i=1}^{n} \sum_{k=1}^{K} \delta_{k i} r_{k i}$ penalty factor to deal with relationship between resource unable to meet quantity and delay damage. Support Resources Optimization Constraint Condition is

\subsection{Transport through constraint}

$$
\sum_{i=1}^{n} r_{k i} Y_{i k} \leq c_{k}, k=1,2, \cdots, K
$$




\subsection{Transport distance constraint}

$$
\sum_{i=0}^{n} \sum_{j=0}^{n} d_{i j} X_{i j k} \leq S, i \neq j, k=1,2, \cdots, K
$$

\subsection{Resource consumption constraint}

$$
\sum_{i=0}^{n} X_{i j k}=Y_{j k}, j=0,1, \cdots, n ; k=1,2, \cdots, K
$$

\subsection{Resource quantity constraint}

$$
Q=\sum_{l=1}^{L} R_{l}+\sum_{i=1}^{n} r_{k i}, k=1,2, \cdots, K
$$

\subsection{Delay time constraint}

$$
\left|s_{k i}+t_{i j k}-s_{k j}\right| \leq\left(1-X_{i j k}\right) B
$$

In the Eq.1-Eq.6, $i, j \in V, k \in K . B$ is a natural number.

\section{Genetic Algorithm Optimization}

Transport strategy optimization initialization. Transport strategy optimization chromosome genes are described by demand node's demand. A single specific transport route is represented of the chromosomal gene permutation. Chromosome gene is produced by random-no repeat way. The feasibility identification of the initial population is carried out by support strategy optimization constraints. The initial population that unable to meet the requirements will be removed. The new population is constructed through the process above. Crossover and mutation process of Population is shown in Fig. 1.

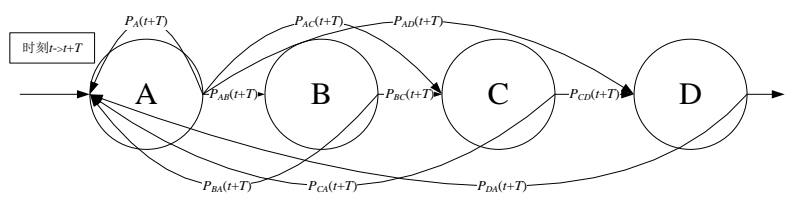

Figure 1. Transport strategy optimized crossover variation diagram

In Fig. 1, $A, B, C, D$ represent the different generations of genetic algorithm. Intergenerational cross probability is probability between different generations’ populations.

\section{Example Analysis}

In order to make the model better describe the military operation other than war, to protect equipment, model parameters are set. In order to facilitate the model operation, support resources, resources transport time, transport distance, money consumption are made as dimension, which are 
called unit resource, unit time, unit distance and unit consumption.

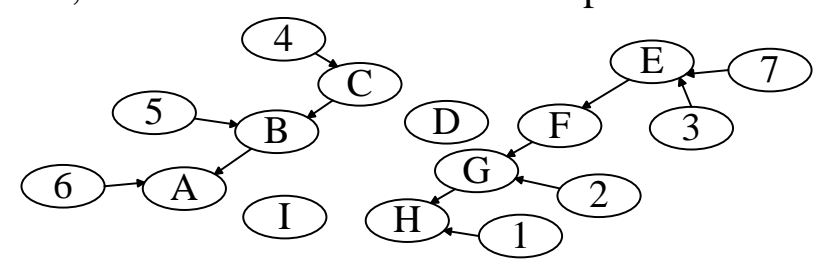

Figure 2. The original military operation other than war mission area road conditions

Resource demand node resources demand that generated by computer random number generator is as Table 2 shown.

Table 2 The Resource Demand Nodes’ Resources Demand Quantity

\begin{tabular}{|l|l|l|l|l|l|l|}
\hline & Apparatusequipment & person & water & food & device \\
\hline A & 0.22 & 0.66 & 0.72 & 0.35 & 0.74 & 0.82 \\
\hline B & 0.38 & 0.4 & 0.73 & 0.25 & 0.63 & 0.77 \\
\hline C & 0.24 & 0.26 & 0.29 & 0.31 & 0.12 & 0.36 \\
\hline D & 0.08 & 0.06 & 0.64 & 0.87 & 0.25 & 0.68 \\
\hline E & 0.43 & 0.28 & 0.32 & 0.63 & 0.55 & 0.31 \\
\hline F & 0.14 & 0.06 & 0.66 & 0.65 & 0.63 & 0.24 \\
\hline G & 0.24 & 0.38 & 0.71 & 0.82 & 0.44 & 0.57 \\
\hline H & 0.36 & 0.04 & 0.69 & 0.36 & 0.25 & 0.81 \\
\hline I & 0.58 & 0.31 & 0.42 & 0.17 & 0.56 & 0.92 \\
\hline
\end{tabular}

In actual calculation, resource demand nodes' resource demand, maximum time to meet, resource need by damaged road repairment etc. initial data is generated by computer random number generator according to disaster situation, as Table 2 shown. Road transport condition and road network plan condition is generated by computer on the basis of initial data. resource demand quantity of damaged $\operatorname{road}^{v_{2}-v_{3}}, v_{3}-v_{6}, v_{4}-v_{5}, v_{7}-v_{9}, v_{9}-v_{15}, v_{0}-v_{13}, v_{11}-v_{12}$ and $v_{20}-v_{21}$ repairment are 2, 3, 1, 4, 9, 4, 6 and 2 respectively.

In model plan, Vehicle speed is constant. Distance between different nodes is set as the value of the measured actual distance. Transport time consumption between different nodes is different. Damaged road can not be used until the road is repaired completely.

Calculation Result Analysis. Each node's demand quantity, resource unable to meet and maximum delay are calculated by computer simulation system on the model set, as Table 2 shown.

Table 3 Nodes’ Demand Data Generation

\begin{tabular}{|l|l|l|l|}
\hline Node code & Demand expectation & $\begin{array}{l}\text { Resource quantity } \\
\text { unable to meet }\end{array}$ & Maximum delay \\
\hline A & 20 & 3.15 & 0.02 \\
\hline B & 13 & 0.14 & 0.32 \\
\hline C & 88 & 4.18 & 1.14 \\
\hline D & 21 & 21 & 0.00 \\
\hline E & 56 & 3.82 & 1.56 \\
\hline F & 44 & 23 & 0.00 \\
\hline G & 13 & 4.21 & 0.14 \\
\hline H & 69 & 2.26 & 0.00 \\
\hline I & 5 & 5 & 0.00 \\
\hline
\end{tabular}


Table 4 Different Chromosome Structures’ Optimization Path

\begin{tabular}{|l|l|}
\hline Chromosome structure & Optimization path \\
\hline 11000110 & $v_{1}-v_{2}-v_{4}-v_{7}$ \\
& $v_{1}-v_{3}-v_{2}$ \\
& $v_{5}-v_{2}-v_{1}-v_{6}$ \\
& $v_{4}-v_{5}$ \\
\hline & $v_{1}-v_{2}-v_{3}-v_{7}$ \\
& $v_{5}-v_{3}-v_{1}$ \\
& $v_{4}-v_{6}-v_{1}-v_{3}-v_{5}-v_{2}$ \\
& $v_{4}-v_{5}-v_{2}$ \\
\hline 11000111 & $v_{1}-v_{3}-v_{7}$ \\
& $v_{5}-v_{3}-v_{1}-v_{6}-v_{7}-v_{4}$ \\
& $v_{4}-v_{1}-v_{3}$ \\
& $v_{4}-v_{2}$ \\
& $v_{1}-v_{5}-v_{2}$ \\
& $v_{2}-v_{6}-v_{3}$ \\
& $v_{1}-v_{7}-v_{4}-v_{3}$ \\
\hline
\end{tabular}

Result is got by road network optimization, as fig.3 shown. The solid line is the road can be used directly after military operation other than war occur.

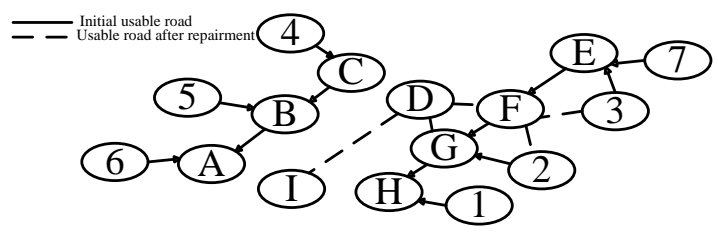

Figure 3. Military operation other than war task region road situation after repairment The optimal transport path schemes are as Table 4 shown.

Table 5 Different Chromosomes’ min z

\begin{tabular}{|l|l|l|l|l|}
\hline & & Chromosome 1 & Chromosome 2 & Chromosome 3 \\
\hline \multirow{2}{*}{$\min Z$} & $\alpha=0.2$ & 52.4 & 96.5 & 65.4 \\
\cline { 2 - 5 } & $\alpha=0.8$ & 87.1 & 204.2 & 68.7 \\
\hline
\end{tabular}

Table 6 Ammunition delivery Support Residual Analysis

\begin{tabular}{|c|c|c|c|}
\hline Index & Load factor & Characteristic value & Interpretation \\
\hline A & 0.871 & \multirow{9}{*}{5.826} & \multirow{9}{*}{$97.4 \%$} \\
\hline B & 0.765 & & \\
\hline $\mathrm{C}$ & 0.742 & & \\
\hline $\mathrm{D}$ & 0.862 & & \\
\hline$E$ & 0.833 & & \\
\hline $\mathrm{F}$ & 0.611 & & \\
\hline $\mathrm{G}$ & 0.386 & & \\
\hline $\mathrm{H}$ & 0.429 & & \\
\hline I & 0.615 & & \\
\hline
\end{tabular}


As seen from Table 5, with the value of delay penalty factor is different, the road network optimization scheme benefit is different. When a small value is chosen for $\alpha$ (for example $\alpha=0.2$ ), $\min z$ is the minimum under the chromosome 1 condition.

\section{Summary}

Aiming at the traditional ammunition delivery support transportation network optimization applied to military operation other than war results in optimization results not converge and poor stability, the ammunition delivery scheduling of network optimization algorithm based on genetic algorithm and Monte-Carlo simulation is put forward. Combined with the characteristics of military operation other than war, ammunition delivery support transportation network scheduling model is constructed by the boundary conditions set, the object function plan, support resource constraints, etc..

\section{References}

[1] W.J. Hurley,J. Brimberg, A. Pavlov, Measuring Ballistic Dispersion for the Purpose of Ammunition Quality Assurance, Springer International Publishing. 15(2017) 11-16.

[2] D. Zlatnik, J. Mareš, Assessment of Effective Ammunition Stock Levels, Land Forces Academy Review. 23(2018) 112-118.

[3] Th. Manning, J. Wyckoff, K. Klingaman, Enhanced propellant performance via environmentally friendly curable surface coating, Defence Technology. 13(2017) 63-71.

[4] L. Eric, T.J. Leonard, Source Identification of Human Exposure to Lead in Nine Cree Nations from Quebec, Canada (Eeyou Istchee territory), Environmental research. 161(2017) 32-46.

[5] D.J. Carr, M. Featherstone, Preliminary Development of A Bleeding Layer to Assess The Effect of A Ballistic Impact on Textile Damage, Forensic science international. 28(2018) 48-52.

[6] A.C. Mark, K.A.J. Doherty, K.T. Stanton. An Investigation Into the Factors That Influence Toolmark Identifications on Ammunition Discharged From Semi-automatic Pistols Recovered From Car fires, Science \& Justice. 57(2017) 1329-1332. 